\title{
Spatiotemporal evolution of venous narrowing in acute MS lesions
}

Philipp Eisele, MD, Kristina Szabo, MD, Anne Ebert, PhD, Wolfgang Brueck, MD, Michael Platten, MD, and Achim Gass, MD

Neurol Neuroimmunol Neuroinflamm March 2018;5:e440. doi:10.1212/NXI.0000000000000440

\author{
Correspondence \\ Dr. Gass \\ achim.gass@medma.uni- \\ heidelberg.de
}

\section{Abstract}

\section{Objective}

To investigate the spatiotemporal evolution of venous narrowing in newly developing MS lesions in a longitudinal MRI study including susceptibility-weighted images (SWIs).

\section{Methods}

We retrospectively investigated serial MR examinations of 18 patients with MS acquired on a 3T MRI system including SWI for acute contrast-enhancing lesions with at least $1 \mathrm{MRI}$ examination before contrast enhancement. The mean diameter of veins at the time point of contrast enhancement was compared with the mean diameter of veins before and after contrast enhancement.

\section{Results}

A total of 40 acute contrast-enhancing lesions with a corresponding intralesional central vein were included in the study. The mean diameter of intralesional veins at the time of contrast enhancement $(0.80 \pm 0.12 \mathrm{~mm})$ was smaller than that at before $(1.16 \pm 0.19 \mathrm{~mm})$ and after contrast enhancement $(1.07 \pm 0.15 \mathrm{~mm} ; p<0.001$ for all comparisons).

\section{Conclusions}

Our findings contribute to the increasing database of plaque development and evolution. The smaller diameter of intralesional veins on SWI at the time of blood-brain barrier breakdown may reflect morphologic changes because of perivascular inflammation and/or decreased levels of deoxygenated hemoglobin.

From the Department of Neurology (P.E., K.S., A.E., M.P., A.G.), Universitätsmedizin Mannheim, University of Heidelberg, Mannheim; and Institute for Neuropathology (W.B.), Universitätsmedizin Göttingen, Germany. 


\section{Glossary}

FLAIR = fluid-attenuated inversion recovery; FOV = field of view; SWI = susceptibility-weighted image; TE = echo time; TI = inversion time; $\mathbf{T R}=$ repetition time.

As early as in the 19th century, pathologic studies reported the perivenous distribution of MS lesions. ${ }^{1}$ The cascade of lesion development includes activation of $\mathrm{T}$ lymphocytes, attachment to the endothelium with subsequent migration through the vessel walls into the perivascular space, and local activation of a cascade of immune responses. ${ }^{2,3}$ Postmortem studies demonstrated that the venous diameter is significantly narrowed in MS lesions as a consequence of perivascular cuffing, fibrosis, and collagen deposition. ${ }^{4,5}$

Susceptibility-weighted imaging (SWI) is an emerging MRI technique that can visualize the cerebral venous architecture because of its sensitivity to the presence of deoxyhemoglobin. ${ }^{6}$ While various MRI studies have demonstrated that penetrating veins can be detected in most MS lesions, ${ }^{7-9}$ only a few cross-sectional MRI studies have reported a decreased venous diameter in MS lesions in a quantitative manner. ${ }^{10,11}$ We investigated the spatiotemporal evolution of the venous appearance in acute MS lesions in a longitudinal fashion, analyzing the venous diameter before, during, and after contrast enhancement in serial MRI data.

\section{Methods}

From our prospectively collected database, we retrospectively screened patients with relapsing-remitting MS being at least 18 years of age who were investigated with serial 3T MRI for the presence of supratentorial acute contrast-enhancing lesions with at least one MRI examination before contrast enhancement. To minimize partial volume effects, only lesions with a minimum diameter of $5 \mathrm{~mm}$ on axial slices were included. Infratentorial lesions were excluded because of limited visualization of veins and image artifacts. Exclusion criteria were presence of neurologic conditions other than MS and missing or unsatisfactory MRI (e.g., due to motion artifacts).

\section{Standard protocol approvals, registrations, and patient consents}

This study was approved by the local ethics committee (2017830R-MA); patient consent was waived because of the retrospective nature of the study and the lack of patient interaction.

\section{MRI}

All MRI studies were conducted on a 3.0T MR system (MAGNETOM Skyra; Siemens, Erlangen, Germany, 20-channel head coil, 50-cm field of view [FOV]). The standardized protocol included a high-resolution 3D magnetization-prepared rapid acquisition gradient-echo sequence (echo time $[\mathrm{TE}]=2.49 \mathrm{~ms}$, repetition time $[\mathrm{TR}]=$ 1,900 milliseconds, inversion time $[\mathrm{TI}]=900$ milliseconds, FOV $240 \times 240 \mathrm{~mm}^{2}$, and spatial resolution $=0.9 \times 0.9 \times$ $\left.0.9 \mathrm{~mm}^{3}\right)$ and a 3D fluid-attenuated inversion recovery (FLAIR) data set $(\mathrm{TE}=398$ milliseconds, $\mathrm{TR}=5,000$ milliseconds, $\mathrm{TI}=1,800$ milliseconds, FOV $240 \times 240 \mathrm{~mm}^{2}$, and resolution $\left.=0.5 \times 0.5 \times 0.9 \mathrm{~mm}^{3}\right)$. SWIs $(\mathrm{TR}=27$ milliseconds, $\mathrm{TE}=20$ milliseconds, FOV $=220 \mathrm{~mm}$, slice thickness $=1.5 \mathrm{~mm}$, and voxel size $=0.9 \times 0.9 \times 1.5 \mathrm{~mm}$ ) were acquired after injection of gadoterate meglumine at a standard dose of $0.1 \mathrm{mmol} / \mathrm{kg}$, which was followed by T1-weighted images ( $\mathrm{TR}=225$ milliseconds $/ \mathrm{TE}=2.5$ milliseconds, $\mathrm{FOV}=220 \mathrm{~mm}$, slice thickness $=3 \mathrm{~mm}$, and voxel size $=0.7 \times 0.7 \times 3.0 \mathrm{~mm}$ ).

\section{Data processing and analysis}

Image postprocessing was performed offline. To facilitate analysis, FLAIR and postcontrast T1-weighted images were coregistered onto the SWIs ("FLAIR/SWIs" and "T1-Gd/ SWIs") using the automated FLIRT (FMRIB's Linear Image Registration Tool), part of FSL (FMRIB's Software Library) (version 5.0.2.1; http://fsl.fmrib.ox.ac.uk/fsl/). ${ }^{12,13}$ Two neurologists with extensive experience in MS imaging (P.E. and A.G.) evaluated all MR images jointly. Readers were unaware of the clinical information. Postcontrast T1-weighted images were investigated for supratentorial acute contrastenhancing parenchymal lesions. The time point of acute contrast enhancement was defined as $t=0$. MRI examinations before contrast enhancement were defined as $t=-1, t=-2$, etc. and follow-up examinations analogous as $t=+1, t=+2$, etc. According to their topography, lesions were classified as periventricular (attached to the walls of the ventricles), paraventricular (located $\leq 3 \mathrm{~mm}$ next to the ventricles), subcortical (located $>3 \mathrm{~mm}$ next to the ventricles), or juxtacortical (attached to the cortex). After lesion identification on postcontrast T1-weighted images, coregistered FLAIR/SWIs and T1-Gd/SWIs were investigated. For every lesion, the presence of a central vein was analyzed. Veins were classified as "deep" (draining into the deep cerebral venous system) or "superficial" (draining into the subarachnoid space) as proposed previously. ${ }^{14}$ Prior and follow-up MRI examinations were evaluated for the presence of the corresponding vein. In addition, in every patient, 4 randomly selected supratentorial veins in the normal-appearing brain tissue that were detectable throughout all MRI examinations were investigated. Calculation of the venous diameter for each time point was performed as described previously. ${ }^{10}$ In short, seed points were placed at the center of each vein on axial slices. The seed points were aligned offline, and the reconstructed vein was displayed in a single reconstructed plane. Venous diameters were measured in 2 different locations, whereas 1 
measurement was taken at the largest diameter and 1 at the smallest. The 2 measurements were averaged to obtain the mean diameter of each vein and used for statistical analysis.

\section{Statistical analysis}

Statistical analysis was performed with IBM SPSS Statistics Version 22. A paired $t$ test was used to compare the venous diameter between $t=0, t=-1$, and $t=+1$, as well as to compare $t=-1$ and $t=+1$. Because only a small number of veins had more than 1 prior or follow-up MRI examination, no further statistical analysis was performed between these time points. Unless otherwise noted, all results are reported as mean \pm SD.

\section{Results}

Overall, we identified 70 patients with MS who were investigated with serial MRI including SWI. In 52/70 patients with MS, no contrast-enhancing lesions were detectable; these patients were excluded. In the remaining 18 patients with relapsing-remitting MS ( 7 men and 11 women, mean age $33 \pm 10$ years, median Expanded Disability Status Scale score $2 \pm 1.5$, mean disease duration $1.5 \pm 1.5$ years) with at least 1 prior 3T MRI examination including SWI (range 1-3 prior MRI examinations), we identified a total of 54 acute contrastenhancing lesions. Fifteen of 18 patients were on best individually selected treatment with natalizumab $(\mathrm{n}=2)$, fingolimod $(n=2)$, dimethyl fumarate $(n=8)$, or interferon- $\beta$ $(n=3)$. In 14/54 (26\%) lesions, no central vein was visible on SWI; these lesions were excluded. The remaining 40 (74\%) lesions were included for further analysis. In 29/40 cases, at least 1 follow-up (range 1-4) 3T MRI examination was available, resulting in a total of $166 \mathrm{MRI}$ examinations. Ten of $40(25 \%)$ lesions were classified as periventricular, 8/40 (20\%) as paraventricular, $16 / 40(40 \%)$ as subcortical, and $6 / 40(15 \%)$ as juxtacortical lesions. Twenty-four of 40 (60\%) veins were classified as "deep" and 16/40 as "superficial." The mean intervals between MRI examinations were as follows: $t=$ -1 : 7 months prior contrast enhancement (range 1-30 months), $t=-2: 15$ months prior contrast enhancement (range 4-30 months), $t=-3: 21$ months prior contrast enhancement (range 8-35 months), $t=+1: 5.5$ months after contrast enhancement (range 3-14 months), $t=+2$ : 10 months after contrast enhancement (range 4-20 months), and $t=+3: 19$ months after contrast enhancement (range 15-26 months).
The mean venous diameters for all time points are presented in table. The mean intralesional venous diameter was smaller at the time of acute contrast enhancement $(0.80 \pm 0.12 \mathrm{~mm})$ than before $(1.16 \pm 0.19 \mathrm{~mm} ; p<0.001)$ and after contrast enhancement $(1.07 \pm 0.15 \mathrm{~mm} ; p<0.001)$. The mean venous diameter was still smaller on follow-up examinations after contrast enhancement had seized $(1.07 \pm 0.15 \mathrm{~mm})$ when compared with the venous diameter before contrast enhancement $(1.16 \pm 0.19 \mathrm{~mm} ; p=0.021)$. However, the mean venous diameter of extralesional veins located in the normalappearing brain tissue $(t=0: 1.13 \pm 0.11 \mathrm{~mm}, t=-1: 1.11 \pm$ $0.14 \mathrm{~mm}$, and $t=+1: 1.12 \pm 0.16 \mathrm{~mm}$ ) did not statistically differ between MRI examinations ( $p>0.05$ for all comparisons). Figure 1 shows a box plot of the venous diameter of 7 MRI examinations in chronological order. Figures 2 and 3 demonstrate examples of venous narrowing at the time of acute contrast enhancement.

\section{Discussion}

There has been an increasing interest in the fine structure of MS lesions because MS studies at 7T repeatedly demonstrated veins in the center of MS lesions. ${ }^{9,11,15}$ This pathologically well-known feature of MS lesions was also seen and confirmed in experimental autoimmune encephalomyelitis. ${ }^{14}$ In addition, a recent study demonstrated that the venous diameter is significantly smaller in MS lesions when compared with the diameter of extralesional veins on gradient-echo $\mathrm{T} 2{ }^{*}$ MRI. ${ }^{10}$ Our results in the present study are very much in line with those findings in that we also identified central veins in the majority of acute contrast-enhancing lesions and that there is apparently venous narrowing detectable in acute contrast-enhancing MS lesions when compared with the venous diameter before blood-brain barrier breakdown. These findings are of interest for several reasons.

Our study was performed on a clinical 3T MRI system using commercially available sequences and postprocessing techniques. This study demonstrates that there is a good chance to detect veins in contrast-enhancing lesions (74\% in this data set), as it has been demonstrated repeatedly before for T2 hyperintense lesions. The combination of contrast enhancement and the visualization of a central vein may well increase the specificity of MRI in MS. This will need to be further explored in larger prospective studies.

Table Characteristics of intralesional veins

\begin{tabular}{|c|c|c|c|c|c|c|c|}
\hline & $t=-3$ & $t=-2$ & $t=-1$ & $t=0$ & $t=+1$ & $t=+2$ & $t=+3$ \\
\hline No. of veins, $n$ & 5 & 11 & 40 & 40 & 29 & 25 & 16 \\
\hline Diameter, mm & $1.10 \pm 0.14$ & $1.19 \pm 0.23$ & $1.16 \pm 0.19$ & $0.80 \pm 0.12^{a}$ & $1.07 \pm 0.15^{b}$ & $1.14 \pm 0.17$ & $1.11 \pm 0.10$ \\
\hline \multicolumn{8}{|c|}{$\begin{array}{l}\text { Measurements are given as mean } \pm \text { overall SD. } \\
\text { a } p<0.001 \text { compared with } t=-1 \text { and } t=+1 \\
{ }^{\mathrm{b}} p<0.05 \text { compared with } t=-1\end{array}$} \\
\hline
\end{tabular}




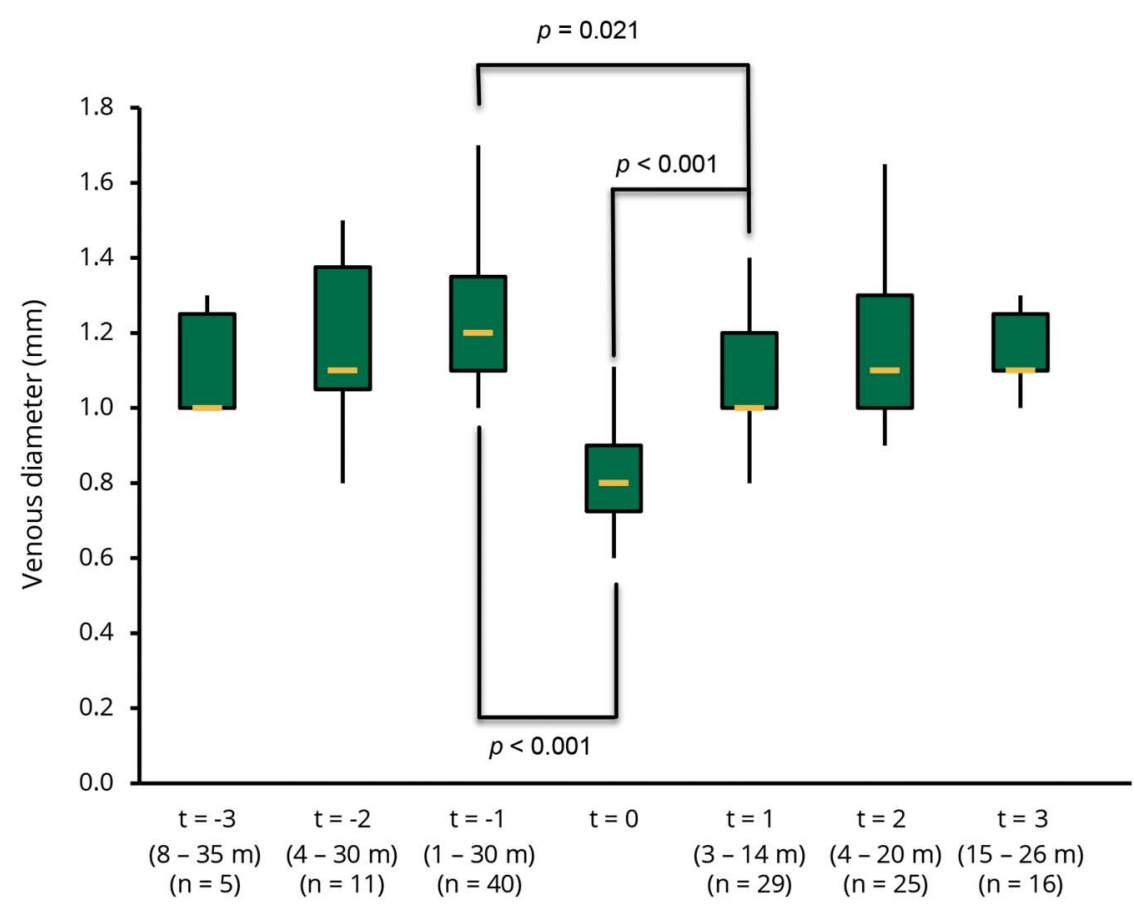

Box plot of the venous diameter of 7 MRI examinations in chronological order. X-axis: relative time points for comparison with $t=0$, range of intervals as given below in months (m). The number of analyzed veins ( $\mathrm{n}$ ) is given below. Y-axis: venous diameter $(\mathrm{mm})$.
Although a recent expert panel remained conservative in regard to the inclusion of the demonstration of central veins to the diagnostic criteria of $\mathrm{MS},{ }^{16}$ there appears to be increasing evidence on the differential diagnostic value of such findings, which may well fit into the picture of a suspected MS. ${ }^{17,18}$ A contrast-enhancing lesion with a central vein may well increase the diagnostic certainty.

The more is known about the underlying pathophysiologic mechanisms in focal lesions, the easier it may become in the future to determine the characteristic pathology. In this regard, the finding of narrowing of veins is of interest. One may consider several possible explanations for this phenomenon.

SWI, a velocity-corrected 3-dimensional gradient-echo sequence, ${ }^{19}$ is a blood-oxygen-level-dependent emerging MRI technique that visualizes changes in magnetic susceptibility caused by different paramagnetic substances. ${ }^{20}$ Because of its sensitivity to deoxyhemoglobin, SWI has the potential to demonstrate both changes in brain oxygen metabolism and venous architecture. In acute ischemic stroke, a relative increase in the deoxyhemoglobin level caused by an imbalance between oxygen supply and demand in hypoperfused areas results in a prominent hypointense signal in the draining veins on $\mathrm{SWI}{ }^{21,22}$ whereas in status epilepticus, reduced venous signals due to increased levels of oxygenated hemoglobin as a consequence of an increased demand with corresponding hyperperfusion have been reported. ${ }^{23,24}$ In MS, dynamic susceptibility contrast perfusion studies have reported signs of increased perfusion in acute contrast-enhancing lesions compared with the normal-appearing white matter. ${ }^{25,26}$ In one study, the authors suggest that increased perfusion was detectable even before contrast enhancement. ${ }^{27}$ Theoretically, increased levels of oxygenated hemoglobin due to an increased metabolic demand in acute contrast-enhancing lesions could result in reduced venous signal on SWI, and a previous study reported reduced visibility of periventricular white matter veins in patients with MS compared with healthy controls. ${ }^{28}$

More direct morphologic evidence of venous narrowing has been demonstrated in histopathologic MS studies of subcortical white matter lesions in which inflammation around small veins are commonly found. ${ }^{29,30}$ Perivascular inflammation consisting of inflammatory cells, fibrinoid, exudate, and perivenous iron deposition within and around the vessel wall forms a perivascular cuff. ${ }^{4,5}$ In addition to the edematous accumulation of interstitial fluid due to blood-brain barrier permeability changes, tissue swelling of contrastenhancing lesions might cause compression of intralesional veins. In acute MS lesions, a dense infiltration of macrophages and $\mathrm{T}$ lymphocytes in the white matter and in small vessels has been described, which could contribute to venous luminal narrowing. $^{31-33}$ In chronic lesions, venous narrowing is thought to represent a consequence of intimal hyperplasia, fibrosis, and collagenous thickening. ${ }^{4,10}$ Our results are in line with these findings as we observed significantly decreased venous diameters at the time of acute blood-brain barrier breakdown and contrast enhancement. On follow-up examinations, the mean venous diameter showed a partial recovery but still remained significantly smaller compared with the diameter before contrast enhancement. One might hypothesize that venous narrowing in acute contrast-enhancing lesions is at 
$\mathrm{t}=-32$ months

$\mathrm{t}=-19$ months

$\mathrm{t}=0$ $\mathrm{t}=6$ months

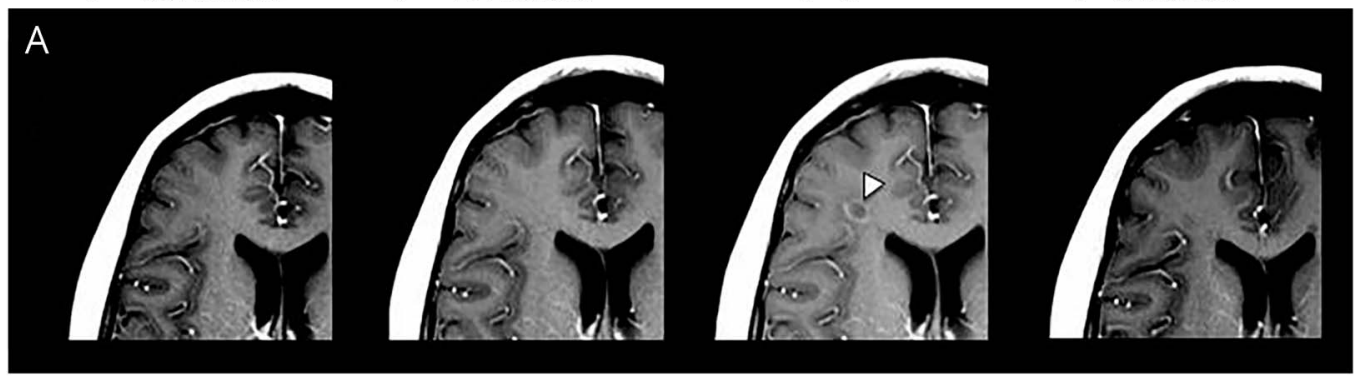

\section{B}
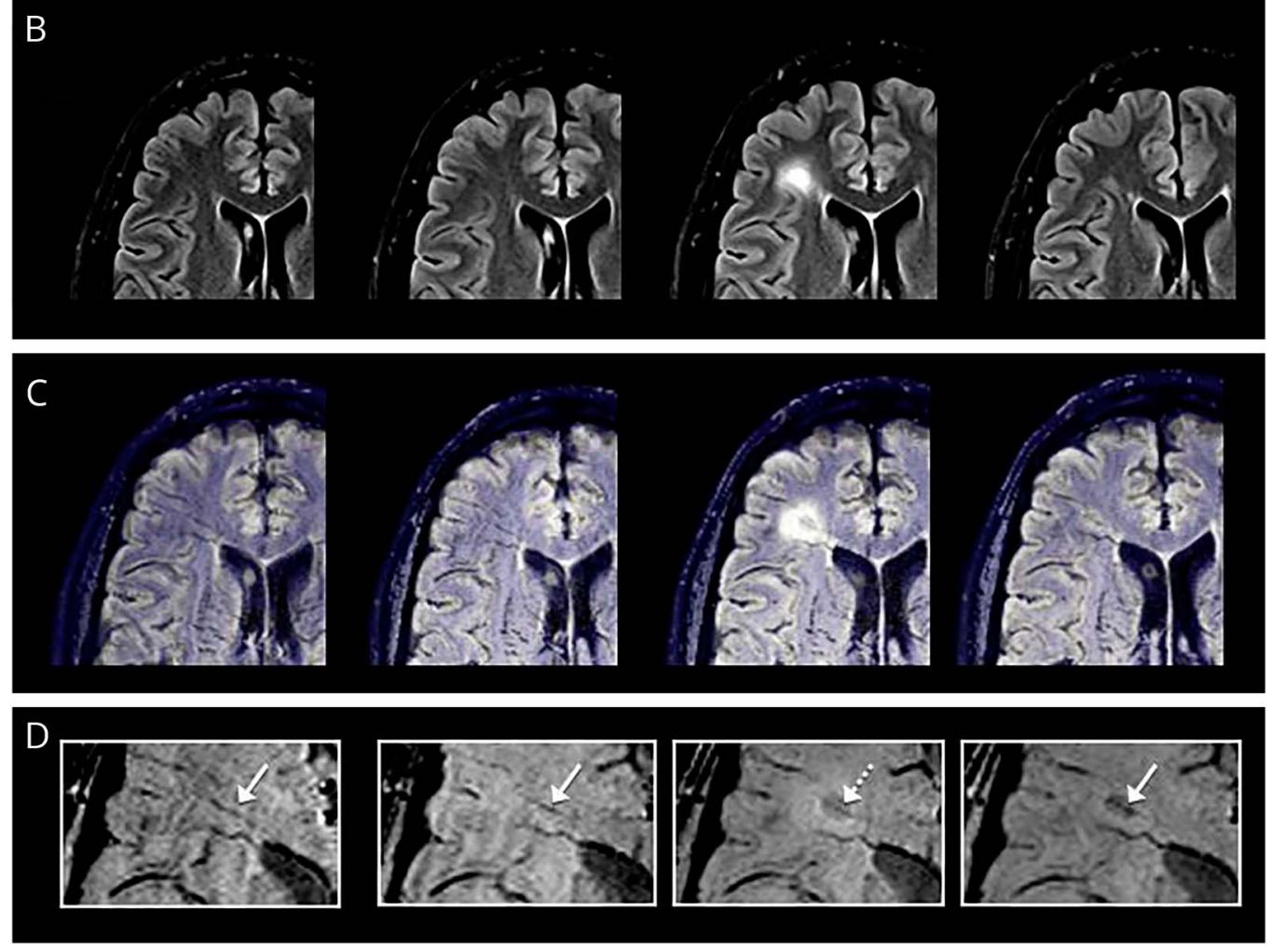

Exemplary serial MRI examinations in a 34-year-old man with relapsing-remitting MS (disease duration at the time of acute contrast enhancement: 4 years, Expanded Disability Status Scale score: 2.5). (A) Postcontrast T1-weighted images demonstrate an acute contrast-enhancing lesion ( $t=0$; white arrowhead). (B) The lesion is prominently hyperintense on fluid-attenuated inversion recovery (FLAIR) images. Coregistered FLAIR-/susceptibility-weighted images (SWIs) (C) and magnified SWIS (D) demonstrate the central vein (dotted arrow; $t=0$ ). At the time of contrast enhancement $(t=0)$, the venous diameter is significantly smaller $(0.85 \mathrm{~mm})$ compared with the MRI examination before contrast enhancement $(t=-19$ months; venous diameter: $1.3 \mathrm{~mm})$ and after contrast enhancement ( $t=+6$ months; venous diameter: $1.0 \mathrm{~mm}$; white arrows).

least partially related to a structural phenomenon before repair and degenerative mechanisms in chronic lesions set in.

However, this study is not without limitations: This was a retrospective study, and the sample size was relatively small. Future longitudinal studies including more patients may consolidate our findings. To describe the fine detail of lesions and veins, high image resolution and exact repositioning are very important to describe the venous detail, and this was performed very carefully, as it is such an important element of follow-up studies. The longitudinal study approach when patients serve as their own control may further underline the validity of the measurements. Certainly, this is an initial and preliminary observation in a serial study, which will need further confirmation with a dedicated higher resolution MRI protocol and/or serial 7T study. Another limitation is that SWI data sets were acquired after gadolinium administration, and therefore, the extent of venous narrowing might be underestimated in our study because gadolinium shortens $\mathrm{T} 1$ relaxation and might enlarge hypointense vessels on SWI as a consequence of a "blooming effect." Furthermore, blood-brain barrier breakdown at the time of contrast enhancement and leakage of gadolinium might result in venous enlargement. We found the smallest venous diameter at the time point of acute contrast enhancement, and therefore, we think it is unlikely that these observations might have influenced our results. Indeed, the mean diameters of intralesional veins in our study are very 

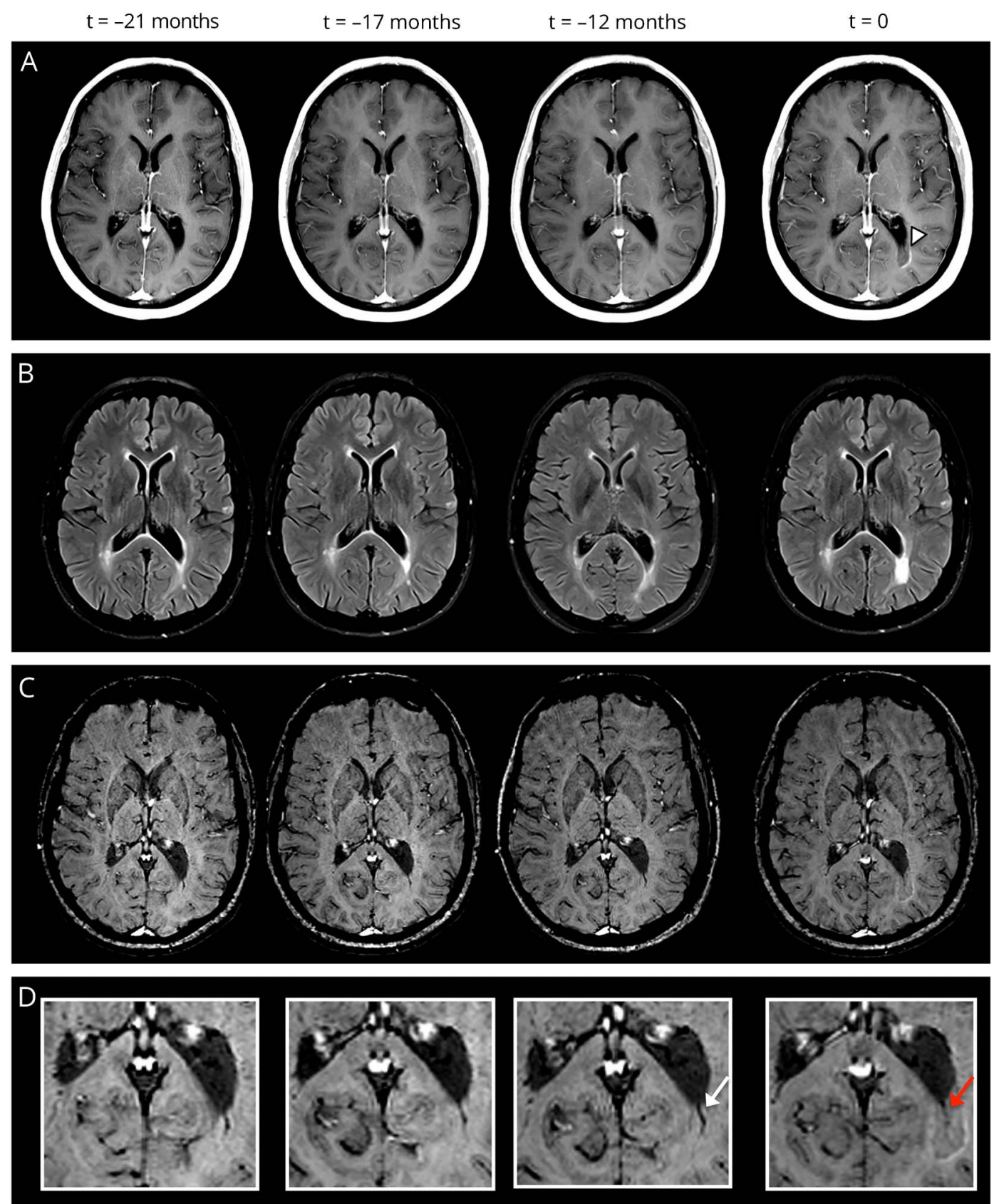

Exemplary serial MRI examinations in a 41-year-old woman with relapsing-remitting MS (disease duration at the time of acute contrast enhancement: 5 years, Expanded Disability Status Scale score: 3.5). (A) Postcontrast T1-weighted images demonstrate an acute contrast-enhancing lesion ( $t=0$; white arrowhead). (B) The lesion is prominently hyperintense on fluid-attenuated inversion recovery images. Susceptibility-weighted images (C) and magnification (D) demonstrate the central vein (red arrow; $t=0$ ). At the time of contrast enhancement, the venous diameter is significantly smaller $(0.7 \mathrm{~mm})$ compared with the MRI examination before contrast enhancement ( $t=-12$ months; venous diameter: $1.1 \mathrm{~mm}$, white arrow).

much comparable with the diameter obtained by another group that has used slightly different data acquisition strategies for the assessments in their patients. ${ }^{10}$ Further technical improvement and more detailed anatomical visualization using 7T MRI or other approaches should explore venous narrowing in acute MS lesions in the future.

Our data demonstrate that the diameter of veins in MS lesions is significantly smaller at the time point of blood-brain barrier breakdown compared with that at time points before and after acute contrast enhancement. Therefore, our findings contribute to the extending knowledge of spatiotemporal plaque development and evolution.

\section{Author contributions}

Philipp Eisele: conceptualization of the study, acquisition, analysis and interpretation of data, and drafting and revising the manuscript. Kristina Szabo: analysis and interpretation of 
data and revising the manuscript. Anne Ebert: analysis and interpretation of data, revising the manuscript, and statistical analysis. Wolfgang Brueck: analysis and interpretation of data and revising the manuscript. Michael Platten: analysis and interpretation of data and revising the manuscript. Achim Gass: conceptualization of the study, acquisition, analysis, and interpretation of data, and drafting and revising the manuscript.

\section{Study funding}

No targeted funding reported.

\section{Disclosure}

P. Eisele received travel expenses from Bayer Healthcare. K. Szabo served on the editorial board of Cerebrovascular Diseases and received research support from the German Research Foundation. A. Ebert reports no disclosures. Wolfgang Brueck served on the scientific advisory board of Genzyme, Novartis, Biogen, and Teva Pharma; received speaker honoraria from Teva, Sanofi, Genzyme, Novartis, Merck Serono, Biogen, Roche, and Bayer; is an editorial board member of Therapeutic Advances in Neurological Disorders and Multiple Sclerosis International and Neuropathology and Applied Neurobiology; and received research support from Teva Pharma, Novartis, Biogen, Genzyme, Meday, the German Research Foundation, German Ministry for Education and Research, the Tschira Foundation, and the German Multiple Sclerosis Foundation. M. Platten served on the scientific advisory board of Roche, Novartis, Merck, Genentech, and Bayer; received travel funding and/or speaker honoraria from Novartis, Teva, Medac, Bayer, and Merck; served on the editorial board of Neuro-Oncology, Journal of Immunotherapy of Cancer, International Journal of Tryptophan Research, Amino Acids, and PLoS One; holds patents for mutation-specific brain tumor diagnostics and vaccines, and Tryptophan metabolism as a diagnostic tool and therapeutic target; consulted for Incyte and Bayer; received research support from Pfizer, Bayer, DFG, BMBF, EU, NCT, DKFZ, Schwiete-Stiftung, and Cancer Aid; and received license fee payments/royalty payments from mutation-specific brain tumor diagnostics and vaccines and tryptopham metabolism as a diagnostic tool and therapeutic target. A. Gass received speaker honoraria/travel funding from Bayer, Biogen, Merck, Novartis, and Roche; is assistant editor of Journal of Neurosciences; and is on the editorial board of Journal of Neuroimaging. Go to Neurology.org/NN for full disclosure forms.

Received July 3, 2017. Accepted in final form November 6, 2017.

\section{References}

1. Rae-Grant AD, Wong C, Bernatowicz R, Fox RJ. Observations on the brain vasculature in multiple sclerosis: a historical perspective. Mult Scler Relat Disord 2014;3: $156-162$.

2. Hemmer B, Archelos JJ, Hartung HP. New concepts in the immunopathogenesis of multiple sclerosis. Nat Rev Neurosci 2002;3:291-301.

3. Wuerfel J, Haertle M, Waiczies $H$, et al. Perivascular spaces-MRI marker of inflammatory activity in the brain? Brain 2008;131:2332-2340.
4. Adams CW, Poston RN, Buk SJ, Sidhu YS, Vipond H. Inflammatory vasculitis in multiple sclerosis. J Neurol Sci 1985;69:269-283.

5. Adams CW. Perivascular iron deposition and other vascular damage in multiple sclerosis. J Neurol Neurosurg Psychiatry 1988;51:260-265.

6. Reichenbach JR, Venkatesan R, Schillinger DJ, Kido DK, Haacke EM. Small vessels in the human brain: MR venography with deoxyhemoglobin as an intrinsic contrast agent. Radiology 1997;204:272-277.

7. Grabner G, Dal-Bianco A, Schernthaner M, Vass K, Lassmann H, Trattnig S. Analysis of multiple sclerosis lesions using a fusion of 3.0 T FLAIR and 7.0 T SWI phase: FLAIR SWI. J Magn Reson Imaging 2011;33:543-549.

8. Tan IL, van Schijndel RA, Pouwels PJ, et al. MR venography of multiple sclerosis. AJNR Am J Neuroradiol 2000;21:1039-1042.

9. Dal-Bianco A, Hametner S, Grabner G, et al. Veins in plaques of multiple sclerosis patients-a longitudinal magnetic resonance imaging study at 7 Tesla. Eur Radiol 2015;25:2913-2920.

10. Gaitan MI, de Alwis MP, Sati P, Nair G, Reich DS. Multiple sclerosis shrinks intralesional, and enlarges extralesional, brain parenchymal veins. Neurology 2013;80: 145-151.

11. Muller K, Kuchling J, Dorr J, et al. Detailing intra-lesional venous lumen shrinking in multiple sclerosis investigated by sFLAIR MRI at 7-T. J Neurol 2014;261:2032-2036.

12. Jenkinson M, Smith S. A global optimisation method for robust affine registration of brain images. Med Image Anal 2001;5:143-156.

13. Jenkinson M, Bannister P, Brady M, Smith S. Improved optimization for the robust and accurate linear registration and motion correction of brain images. Neuroimage 2002;17:825-841.

14. Gaitan MI, Maggi P, Wohler J, et al. Perivenular brain lesions in a primate multiple sclerosis model at 7-tesla magnetic resonance imaging. Mult Scler 2014;20:64-71.

15. Kilsdonk ID, Wattjes MP, Lopez-Soriano A, et al. Improved differentiation between MS and vascular brain lesions using FLAIR* at 7 tesla. Eur Radiol 2014;24:841-849.

16. Filippi M, Rocca MA, Ciccarelli O, et al. MRI criteria for the diagnosis of multiple sclerosis: MAGNIMS consensus guidelines. Lancet Neurol 2016;15:292-303.

17. Chawla S, Kister I, Wuerfel J, et al. Iron and non-iron-related characteristics of multiple sclerosis and neuromyelitis optica lesions at 7T MRI. AJNR Am J Neuroradiol 2016;37:1223-1230.

18. Sati $\mathrm{P}, \mathrm{Oh} \mathrm{J}, \mathrm{Constable} \mathrm{RT,} \mathrm{et} \mathrm{al.} \mathrm{The} \mathrm{central} \mathrm{vein} \mathrm{sign} \mathrm{and} \mathrm{its} \mathrm{clinical} \mathrm{evaluation} \mathrm{for} \mathrm{the}$ diagnosis of multiple sclerosis: a consensus statement from the North American Imaging in Multiple Sclerosis Cooperative. Nat Rev Neurol 2016;12:714-722.

19. Haacke EM, Mittal S, Wu Z, Neelavalli J, Cheng YC. Susceptibility-weighted imaging: technical aspects and clinical applications, part 1. AJNR Am J Neuroradiol 2009;30: 19-30.

20. Haacke EM, Makki M, Ge Y, et al. Characterizing iron deposition in multiple sclerosis lesions using susceptibility weighted imaging. J Magn Reson Imaging 2009;29: 537-544.

21. Mittal S, Wu Z, Neelavalli J, Haacke EM. Susceptibility-weighted imaging: technical aspects and clinical applications, part 2. AJNR Am J Neuroradiol 2009;30:232-252.

22. Baik SK, Choi W, Oh SJ, et al. Change in cortical vessel signs on susceptibilityweighted images after full recanalization in hyperacute ischemic stroke. Cerebrovasc Dis 2012;34:206-212.

23. Aellen J, Abela E, Buerki SE, et al. Focal hemodynamic patterns of status epilepticus detected by susceptibility weighted imaging (SWI). Eur Radiol 2014;24:2980-2988.

24. Eisele P, Gass A, Alonso A, Wolf ME, Griebe M, Szabo K. Susceptibility-weighted MRI signs of compensatory mechanism in nonconvulsive status epilepticus. Neurology 2016;87:116-117.

25. Haselhorst R, Kappos L, Bilecen D, et al. Dynamic susceptibility contrast MR imaging of plaque development in multiple sclerosis: application of an extended blood-brain barrier leakage correction. J Magn Reson Imaging 2000;11:495-505.

26. Ge Y, Law M, Johnson G, et al. Dynamic susceptibility contrast perfusion MR imaging of multiple sclerosis lesions: characterizing hemodynamic impairment and inflammatory activity. AJNR Am J Neuroradiol 2005;26:1539-1547.

27. Wuerfel J, Bellmann-Strobl J, Brunecker P, et al. Changes in cerebral perfusion precede plaque formation in multiple sclerosis: a longitudinal perfusion MRI study. Brain 2004;127:111-119.

28. Ge Y, Zohrabian VM, Osa EO, et al. Diminished visibility of cerebral venous vasculature in multiple sclerosis by susceptibility-weighted imaging at 3.0 tesla. J Magn Reson Imaging 2009;29:1190-1194.

29. Adams CW. The onset and progression of the lesion in multiple sclerosis. J Neurol Sci 1975;25:165-182.

30. Fog T. On the vessel-plaque relationships in the brain in multiple sclerosis. Acta Neurol Scand 1964;40(suppl 10):9-15

31. Bitsch A, Wegener C, da Costa C, et al. Lesion development in Marburg's type of acute multiple sclerosis: from inflammation to demyelination. Mult Scler 1999;5: 138-146.

32. Agrawal SM, Williamson J, Sharma R, et al. Extracellular matrix metalloproteinase inducer shows active perivascular cuffs in multiple sclerosis. Brain 2013;136: $1760-1777$

33. Popescu BF, Pirko I, Lucchinetti CF. Pathology of multiple sclerosis: where do we stand? Continuum 2013;19:901-921. 


\section{Neurology \\ Neuroimmunology \& Neuroinflammation}

Spatiotemporal evolution of venous narrowing in acute MS lesions

Philipp Eisele, Kristina Szabo, Anne Ebert, et al.

Neurol Neuroimmunol Neuroinflamm 2018;5;

DOI 10.1212/NXI.0000000000000440

This information is current as of January 18, 2018

\section{Updated Information \& Services}

References

Subspecialty Collections

Permissions \& Licensing

\section{Reprints}

including high resolution figures, can be found at:

http://nn.neurology.org/content/5/2/e440.full.html

This article cites 33 articles, 4 of which you can access for free at: http://nn.neurology.org/content/5/2/e440.full.html\#\#ref-list-1

This article, along with others on similar topics, appears in the following collection(s):

MRI

http://nn.neurology.org//cgi/collection/mri

Multiple sclerosis

http://nn.neurology.org//cgi/collection/multiple_sclerosis

Information about reproducing this article in parts (figures,tables) or in its entirety can be found online at:

http://nn.neurology.org/misc/about.xhtml\#permissions

Information about ordering reprints can be found online:

http://nn.neurology.org/misc/addir.xhtml\#reprintsus

Neurol Neuroimmunol Neuroinflamm is an official journal of the American Academy of Neurology.

Published since April 2014, it is an open-access, online-only, continuous publication journal. Copyright

Copyright (C) 2018 The Author(s). Published by Wolters Kluwer Health, Inc. on behalf of the American

Academy of Neurology.. All rights reserved. Online ISSN: 2332-7812.

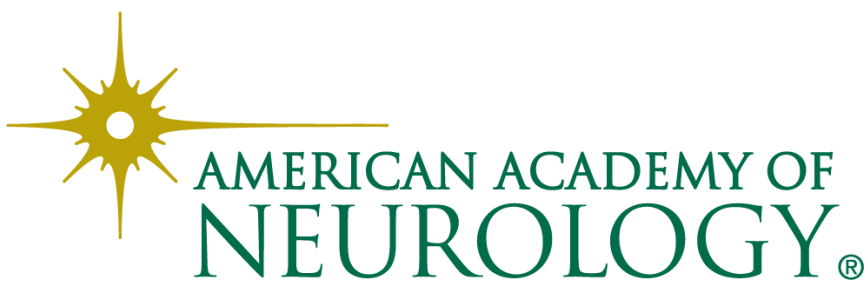

